\title{
KANDUNGAN FORMALIN PADA IKAN BANDENG (Chanos chanos) DI PASAR TRADISIONAL DAN MODERN DI DENPASAR
}

\author{
Dewi Novita Hardaningsih*, Ketut Gede Dharma Putra dan I Wayan Suirta \\ Program Studi Kimia FMIPA Universitas Udayana, Bukit Jimbaran, Badung, Bali 80361 \\ *E-mail: novichem@ymail.com
}

\begin{abstract}
ABSTRAK
Telah dilakukan analisis kandungan formalin pada ikan bandeng di pasar tradisional dan modern di Denpasar. Ikan bandeng (Chanos chanos) diambil pada 4 lokasi yang berbeda dengan 2 lokasi di pasar tradisional dan 2 lokasi di pasar modern. Kandungan formalin dalam sampel dianalisis dengan alat spektrofotometri UV-Vis. Hasil analisis menunjukkan adanya kandungan formalin pada ikan bandeng. Konsentrasi formalin pada ikan bandeng sampel A dan B berturut-turut sebesar 15,16 ppm dan 13,44 ppm sedangkan pada sampel C dan D berturut-turut sebesar 21,85 ppm dan 15,71 ppm.
\end{abstract}

Kata kunci: formalin, ikan bandeng, Chanos chanos, pasar tradisional dan modern

\begin{abstract}
The analysis of formaldehyde content in fish (Chanos Chanos) collected from traditional and modern markets in Denpasar has been conducted at. The samples were collected from two traditional markets and two modern markets. The samples were analyzed by UV-Vis spectrophotometry. In this study, all samples were found to contain formaldehyde. The concentration of formaldehyde in fish samples A and B were 15,16 and 13,44 ppm, respectively while in the samples $C$ and D 21,85 and 15,71 ppm, respectively.
\end{abstract}

Keywords: Chanos Chanos, formaldehyde, , traditional and modern markets

\section{PENDAHULUAN}

Seiring dengan kemajuan teknologi pengolahan pangan saat ini, diperlukan ketelitian dalam pemilihan produk pangan. Terdapat berbagai jenis bahan pengawet dalam pengolahan pangan untuk menjaga daya tahan suatu produk pangan. Zat pengawet berfungsi mengatasi kerusakan tekstur makanan dari segi warna, bau, rasa dan juga untuk menghambat aktivitas bakteri yang merugikan. Bahan pengawet yang beredar di masyarakat yaitu salah satunya formalin. Dengan harga yang relatif murah dan mudah didapat, formalin digunakan sebagai bahan pengawet karena dapat mengawetkan bahan pangan termasuk ikan. Formalin dilarang digunakan sebagai pengawet makanan menurut peraturan Menteri Kesehatan Republik Indonesia Nomor 722 Tahun 1988. Namun, dalam kenyataannya penggunaan formalin sebagai pengawet makanan masih dimanfaatkan oleh sekelompok masyarakat (Zuraidah, 2007).

Dari data 2005, terjadi peningkatan dalam penggunaan formalin pada makanan. Menurut hasil survei, didapat total $11,64 \%$ sampel ikan di lapangan mengandung formalin dengan 7,04\% berupa ikan segar dan 4,6\% berupa ikan asin. Penelitian Badan Pengawas Obat dan Makanan Indonesia (2010), dari total 786 sampel tahu dan bakso mengandung formalin dengan proporsi $16 \%$ dan $15 \%$, mi basah $57 \%$, ikan dan hasil laut menempati peringkat teratas yakni $66 \%$.

Ikan bandeng ditemukan pertama kali oleh Dane Forsskal pada Tahun 1925 di laut merah. Ikan bandeng memiliki nama latin Chanos chanos, dalam bahasa Inggris Milkfish dan Bale Bolu dari bahasa Bugis Makassar. Ikan bandeng memiliki tubuh yang padat, pipih, panjang, oval dan 
ramping menyerupai torpedo. Panjang tubuh ikan bandeng dengan total perbandingan sekitar 1 : $(4,0-5,2)$. Ikan bandeng banyak dijumpai di pasar tradisional dan pasar modern. Ikan bandeng merupakan bahan pangan yang mempuyai komponen gizi yang cukup tinggi dan banyak diminati oleh masyarakat luas, sehingga para pedagang maupun distributor ikan bandeng memanfaatkan pengawetan ikan bandeng dengan menambahkan formalin agar ikan bandeng tetap dalam keadaan segar. Ciri-ciri ikan segar yang mengandung formalin yaitu : warna insang merah tua dan tidak cemerlang, tidak rusak sampai tiga hari pada suhu kamar $\left(25^{\circ} \mathrm{C}\right)$, warna daging ikan putih bersih dan bukan merah segar, tidak ada lalat ataupun serangga yang menghinggapi ikan tersebut dan tekstur daging ikan menjadi kaku sehingga sedikit sulit untuk dibelah atau dipotong. Ciri-ciri di atas dapat memberikan gambaran tentang ciri ikan segar yang diduga mengandung formalin. Ikan seharusnya menjadi sumber kesehatan dan sumber vitamin yang penting bagi tubuh kita. Oleh karena itu kita harus tetap waspada dengan ikan yang kita konsumsi agar tidak mengakibatkan penyakit.

Pada penelitian ini peneliti menganalisis kandungan formalin pada ikan bandeng yang dilakukan pada 2 tempat yaitu ikan bandeng dari pasar tradisional dan pasar modern yang berada di Denpasar. Dari penelitian ini, diharapkan dapat memberikan informasi tentang keamanan pangan kepada masyarakat tentang adanya kandungan formalin pada ikan bandeng yang dijual di pasar tradisional dan modern di Denpasar.

\section{MATERI DAN METODE}

\section{Bahan}

Bahan-bahan penelitan yang digunakan seperti : ikan bandeng, aquades, asam kromatofat $\left(\mathrm{C}_{10} \mathrm{H}_{6} \mathrm{O}_{8} \mathrm{~S}_{2} \mathrm{Na}_{2} 2 \mathrm{H}_{2} \mathrm{O}\right)$ dan formaldehid.

\section{Peralatan}

Alat-alat penelitian yang digunakan seperti : gunting, plastik bening, kertas saring, tabung reaksi, gelas beker, gelas ukur, pipet tetes, pipet mikro, erlemeyer, botol semprot, alat pemanas, pengaduk, stopwatch, neraca analitik, Spektrofotometer UV-Vis.

\section{Cara Kerja \\ Penyiapan bahan}

Sampel ikan bandeng sebanyak 4 buah dari pasar modern (A dan B) dan pasar tradisional (C dan D) yang akan dianalisis di laboratorium. Pengambilan daging pada tubuh bagian tengah. Sampel ikan dipotong kecil-kecil, kemudian masing-masing sampel ditimbang sebanyak $5 \mathrm{~g}$. Dimasukkan ke dalam plastik bening yang selanjutnya akan dianalisis kandungan formalinnya.

\section{Pembuatan Kurva Standar}

Pembuatan kurva standar dibuat dengan konsentrasi formalin yang berbeda yaitu $0 ; 2 ; 4 ; 6$; 8 dan $10 \mathrm{ppm}$. Pembuatan larutan formalin $0,1 \%$ dengan mengambil $2,7 \mathrm{~mL}$ formalin $37 \%$, kemudian dimasukkan ke dalam labu ukur 1000 $\mathrm{mL}$, ditambahkan aquades sampai tanda batas, kemudian diukur absorbansinya dengan UV-Vis.

\section{Analisis Kandungan Formalin Sampel Ikan Bandeng}

Sampel ikan bandeng sebanyak $5 \mathrm{~g}$ digerus menggunakan mortar, ditambahkan aquades sebanyak $20 \mathrm{ml}$ ke dalam sampel ikan, disaring kemudian filtratnya diambil sebanyak $2 \mathrm{ml}$ dan dimasukkan kedalam tabung reaksi. Ditambahkan asam kromatofat sebanyak $5 \mathrm{ml}$ pada masingmasing tabung reaksi. Dipanaskan pada suhu $40^{\circ} \mathrm{C}$ agar mempercepat reaksi antara formalin dan asam kromatofat sehingga menimbulkan warna ungu yang ditandai bahwa terdapat kandungan formalin dalam sampel. Kemudian didinginkan dan absorbansinya diukur dengan alat spektrofotometer $\mathrm{UV}-\mathrm{Vis}$ dengan panjang gelombang $520 \mathrm{~nm}$.

\section{HASIL DAN PEMBAHASAN}

\section{Hasil Pengukuran Absorbansi Larutan Standar Formalin}

Untuk membuat kurva kalibrasi, dilakukan pengukuran absorbansi larutan formalin dengan berbagai konsentrasi yaitu $0 ; 2 ; 4 ; 6 ; 8$ dan 10 ppm menggunakan alat Spektrofotometer UV-Vis. Berdasarkan hukum Lambeert Beer, konsentrasi analit berbanding lurus dengan absorbansi, dimana semakin besar konsentrasi maka semakin besar pula absorbansinya. 
Tabel 1. Hasil Pengukuran Absorbansi Larutan Standar Formalin

\begin{tabular}{ccc}
\hline No. & $\begin{array}{c}\text { Konsentrasi } \\
(\mathrm{ppm})\end{array}$ & Absorbansi \\
\hline 1 & 0 & 0,000 \\
2 & 2 & 0,052 \\
3 & 4 & 0,103 \\
4 & 6 & 0,149 \\
5 & 8 & 0,201 \\
6 & 10 & 0,256 \\
\hline
\end{tabular}

Dari data di atas, dapat dibuat kurva standar untuk larutan formalin seperti ditunjukkan dalam Gambar 1 di bawah ini.

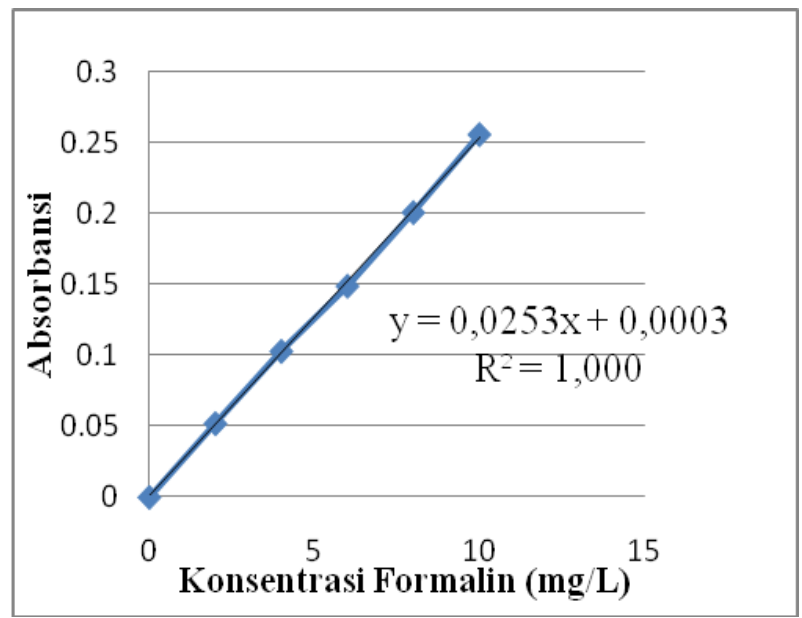

Gambar 1. Kurva Kalibrasi Formalin

\section{Kandungan Formalin dalam Sampel Ikan Bandeng}

Untuk mengetahui konsentrasi formalin total dalam ikan bandeng, maka absorbansi yang terukur dimasukkan ke dalam persamaan regresi linier $\mathrm{y}=0,0253 \mathrm{x}+0,0003$ sehingga diperoleh konsentrasi formalin dalam ikan.

Berdasarkan tabel di bawah dapat dilihat bahwa kandungan formalin dalam sampel ikan bandeng yang diambil dari tempat berbeda memiliki konsentrasi yang berbeda pula. Kandungan formalin paling tinggi yaitu terdapat pada pasar Tradisional (sampel C) dengan kadar formalin sebesar 21,85 ppm. Hal ini menunjukkan bahwa ada beberapa pedagang yang melakukan kecurangan dengan menambahkan formalin sebagai bahan pengawet ikan bandeng selama proses penjualan maupun proses penyimpanan.
Tabel 2. Konsentrasi Formalin dalam Ikan Bandeng

\begin{tabular}{ccc}
\hline $\begin{array}{c}\text { Tempat } \\
\text { pengambilan } \\
\text { sampel }\end{array}$ & $\begin{array}{c}\text { Absorbansi } \\
\text { Formalin } \\
\text { dalam Sampel }\end{array}$ & $\begin{array}{c}\text { Konsentrasi } \\
\text { Formalin } \\
\text { dalam Sampel } \\
\text { (ppm) }\end{array}$ \\
\hline A & 0,3839 & 15,16 \\
B & 0,3404 & 13,44 \\
C & 0,5530 & 21,85 \\
D & 0,4000 & 15,71 \\
\hline
\end{tabular}

Pengambilan sampel A dan B dilakukan di pasar Modern dengan mengambil ikan bandeng yang berada dalam ruang pendingin. Pengambilan sampel C dan D dilakukan di pasar Tradisional dengan mengambil ikan bandeng yang tidak berada dalam ruang pendingin yaitu diletakkan pada tempat terbuka untuk dijual langsung pada pembeli. Alasan pedagang pada pasar Tradisional melakukan proses penyimpanan dengan menambahkan formalin pada ikan yang dijual yaitu ikan bandeng yang ditempatkan pada tempat terbuka ditambah dengan sanitasi lingkungan berjualan yang tidak memenuhi syarat kebersihan sehingga kemungkinan ikan bandeng dapat tercemar oleh bakteri pembusuk dari udara luar. Sedangkan ikan bandeng di pasar Modern semuanya sudah dalam kemasan dan disimpan dalam ruang pendingin dengan sanitasi ruangan yang baik sehingga kemungkinan tercemar bakteri pembusuk akan lebih kecil sehingga dalam penyimpanan ikan dosis penggunaan formalin tidak terlalu tinggi.

Ikan bandeng yang mengandung formalin akan ditunjukkan dengan berubahnya warna sampel ikan dari tidak berwarna menjadi merah muda hingga berwarna ungu. Semakin ungu warna pada sampel berarti kadar formalin yang ada pada ikan semakin tinggi. Pada penelitian kali ini, peneliti menggunakan asam kromatofat untuk mengetahui keberadaan formalin dalam ikan. Asam kromatofat digunakan untuk mengikat formalin agar terlepas dari bahan. Formalin juga bereaksi dengan asam kromatofat menghasilkan senyawa kompleks yang berwarna merah keunguan. Jika dihasilkan warna merah keunguan maka dapat disimpulkan bahwa sampel tersebut mengandung formalin (Widyaningsih dan Murtini., 2006). Berdasarkan kurva analisis kandungan formalin pada ikan bandeng dapat diketahui konsentrasi formalin terdapat pada semua sampel 
ikan bandeng, namun konsentrasi tertinggi terdapat sampel ikan bandeng di pasar tradisional. Keberadaan formalin dalam ikan bandeng dapat merugikan masyarakat yang mengkonsumsinya.

\section{SIMPULAN DAN SARAN}

\section{Simpulan}

Hasil analisis kandungan formalin dalam ikan Bandeng menunjukkan adanya kandungan formalin di setiap tempat pengambilan sampel ikan dengan konsentrasi yang berbeda-beda.

Konsentrasi formalin dalam ikan Bandeng yang terdapat pada sampel A dan B berturut-turut sebesar 15,16 ppm dan 13,44 ppm sedangkan pada sampel C dan D berturut-turut sebesar 21,85 ppm dan $15,71 \mathrm{ppm}$.

\section{Saran}

Berdasarkan hasil penelitian dan kesimpulan dapat disarankan untuk mengontrol dan melakukan pemeriksaan lebih lanjut pada pasar yang diduga menggunakan bahan pengawet berbahaya seperti formalin. Begitu juga kepada masyarakat agar lebih berhati-hati dan teliti dalam memilih ikan yang akan dikonsumsi.

\section{UCAPAN TERIMA KASIH}

Penulis mengucapkan terimakasih kepada A. A. I. A. Mayun Laksmiwati, S.Si., M.Si, Ir. Ni Gusti Ayu Made Dwi Adhi Suastuti, M.Si dan Dr. I Wayan Gede Gunawan, S.Si., M.Si selaku dosen penguji yang telah memberikan bimbingan dan dukungan moral kepada penulis dan kepada Laboratorium Penelitian Program Studi Kimia FMIPA Universitas Udayana.

\section{DAFTAR PUSTAKA}

Astawan, M., 2004, Ikan Yang Sedap dan Bergizi, Pustaka Mandiri, Solo

Badan BPOM RI, 2006, Mengenal Formalin dan Bahayanya, Denpasar, Bali Post, 2016

Badan Standardisasi Nasional, 2006, Standar Nasional Indonesia No. 01-2729.1-2006 Mutu Ikan Segar, Jakarta
Departemen Kesehatan RI, 1989, Peraturan Menteri Kesehatan RI No.722/MenKes/Per/IX/1988, Tentang Bahan Tambahan Makanan, Departemen Kesehatan RI, Jakarta

Fagnani, E., Melios, C.B., Pezza L., and Pezza H.R., 2003, Chromotropic acidformaldehyde reaction in strongly acidic media.The role of dissolved oxygen and replacement of concentrated sulfuric acid, Talanta, $60: 171-176$

Irianto, M., 2006, Ikan Berformalin Berbahaya.(http://kesehatan.kompasiana.c om/medis/2012/02/22/ikan berformalin)

Purnomowati, I., Hidayati, D., dan Saparinto, C., 2007, Ragam Olahan Bandeng, Kanisius, Yogyakarta

Rohman, A. dan Sumantri, 2007, Analisis Makanan, Gajah Mada University Press, Yogyakarta

Saanin, H., 1984, Taksonomi dan Kunci Identifikasi Ikan, Jilid I-II, Edisi II, Bina Cipta, Bogor

Widianarko, B., 2000, Seri Iptek Pangan Volume 1: Teknologi Produk, Nutrisi dan Keamanan Pangan, Jurusan Teknologi Pangan - Unika Soegiojapranata, Semarang

Widyaningsih, D.T. dan Erni, 2006, Formalin, Penerbit Trubus Agrisarana, Surabaya

Yuliani, S., 2007, Formalin dan Masalahnya, Warta Penelitian dan Pengembangan Pertanian, 29 (5) : 7-9

Zuraidah, Y., 2007, Faktor-Faktor Yang Berhubungan Dengan Penggunaan Formalin Pada Pedagang Tahu Dipasar Flamboyan Kota Pontianak, Jurusan Gizi Politeknik Kesehatan Depkes 